\title{
Membrane Filtration of Methyl Orange
}

\section{Levent Semiz ${ }^{1 *}$}

\begin{abstract}
In this work, the filtration of methyl orange by polyacrylonitrile-co-poly(2ethylhexylacrylate) copolymer and polyacrylonitrile-co-poly(2-ethylhexylacrylate)/polyaniline membranes were utilized. It was observed that the filtration performance was improved as acrylonitrile amount in the copolymer increased. Also, functionalizing membrane with polyaniline further enhanced the dye rejection rates. Moreover, this enhancement was proportional to polyaniline amount. Furthermore, the performance of polyaniline containing membranes was $\mathrm{pH}$ dependent. They showed higher filtration performances at acidic mediums and they further increased as $\mathrm{pH}$ decreased. PAN(92)-co-P2EHA(8)- PANI(10\%) membrane provided 99.3\% dye rejection value for 25 ppm dye concentration at $\mathrm{pH} 2$. Also, this membrane demonstrated good resistance to permeate concentration. It had $97.6 \%$ and $90.1 \%$ dye rejection rates for 50 and 100 ppm, respectively.
\end{abstract}

Keywords: Dye, filtration, membrane, methyl orange

\footnotetext{
${ }^{1}$ Levent SEMIZ (Orcid ID: 0000-0002-3218-4663), Amasya University, Vocational School of Technical Sciences, Department of Chemistry and Chemical Process Technology, Amasya, Turkey

*Sorumlu Yazar/Corresponding Author: Levent SEMIZ, e-mail: levent.semiz@amasya.edu.tr
}

Geliş tarihi / Received: 02-04-2019

Kabul tarihi / Accepted: 11-09-2019 


\section{INTRODUCTION}

Clean water is an important issue for the environment and human health. Water pollution is a growing problem due to the decrease in clean water resources and increase in industrial progresses leading to higher wastewater. Among pollutants, dyes are one of the most water polluting waste. Dye utilizing industries such as textile, paint, leather, pharmaceutical, cosmetics and plastics cause more than $7 \times 10^{5}$ ton wastewater annually (Li et al., 2015; Chen et al., 2015; Han et al., 2016; Karthik et al., 2014; Ahmad et al., 2015; Xing et al., 2015). These wastewaters are a severe threat for the environment, especially aquatic enviroment, and so for human health (Thong et al., 2018; Manimaran et al., 2018; Kumar et al., 2015). Dyes in water decreases the transmittance of light into the water and dissolved oxygen amount in aquatic environment which are essential for aquatic life (Luo et al., 2010). Moreover, azo dyes like methyl orange are carcinogenic (Kumar et al., 2018). Hence, the removal of dyes for the wastewater treatment is an important issue that should be held seriously for the environment and human health (Xu et al., 2018).

There are various methods for the removal of dyes from wastewater. Primary ones consist of oxidation, extraction, adsorption, biological treatment, ozonization, floatation, degredation, electrophoresis, coagulation, flocculation, ion-exchange, and membrane filtration (Kertesz et al., 2014; Wang et al., 2015; Ou et al., 2015; Panthi et al., 2015; Chen et al., 2018; Gao et al., 2013; Nabil et al., 2014; Liu et al., 2017; Jiang et al., 2015; Zhang et al., 2017). However, these removal methods include drawbacks such as high operation costs, low efficiency, high energy necessity, poor selectivity, technical application problems, On the other hand, membrane filtration lead to low energy requirement, low cost, lower seondary pollution, high removal efficiency, good selectivity, environmentally friendly application advantages (Chen et al., 2018; Foorginezhad and Zerafat, 2017; Aouni et al., 2012; Ong et al., 2014; Xu et al., 2016; Liu et al., 2017; Lin et al., 2015; Yao et al., 2016; Nayak et al., 2018 ; Zhang et al., 2019). In literature, different membranes have been utilized in methyl orange filtration from wastewater such as graphene oxide (GO)-nylon 6 (Chen et al., 2018), polyacrylonitrile (PAN)-tannic aci-cupric acetate (Chakrabarty et al., 2017), PAN-diamino piperazinetrimesoyl chloride (Perez-Manriquez et al., 2015), polyvinylidene difluoride (PVDF) (Mertens et al., 2018), polysulfone-polydopamine (PDA)-chitosan- $\mathrm{SiO}_{2}$ (Ding et al., 2017), polyamide 6-GO (Chen et al., 2018), poly(arylene ether sulfone)-polyacrylic acid (Zhu et al., 2016), PAN- magnesium silicateGO (Liang et al., 2016), PDA-polyethyleneimine-FeOOH (Lv et al., 2017), polyurethane-humic acidchitosan (Yang et al., 2017), PAN-GO (Fathizadeh et al., 2017) and chitosan-carbon nanotube (Shi et al., 2016).

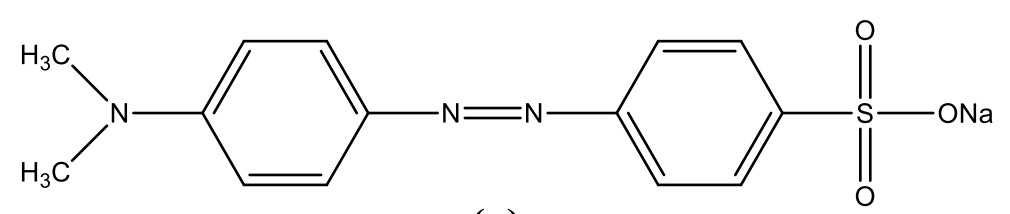

(a)

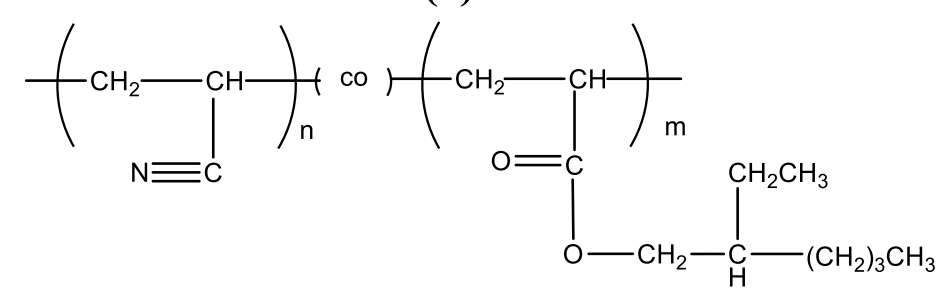

(b)

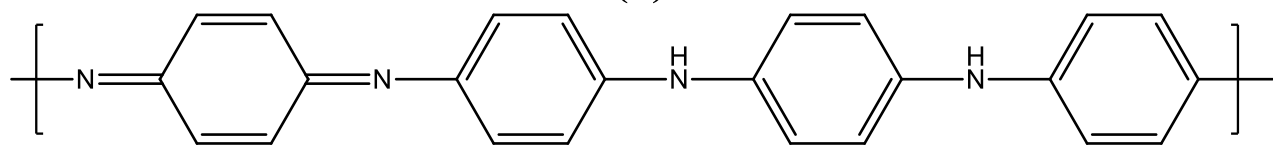

(c)

Figure 1. Chemical structures of (a) methyl orange, (b) polyacrylonitrile-co-poly(2-ethylhexylacrylate) and (c) polyaniline 
In this study, methyl orange, an azo dye, filtration were utilized by polyacrylonitrile-co-poly(2ethylhexylacrylate) copolymer and polyacrylonitrile-co-poly(2-ethylhexylacrylate)-polyaniline blend membranes (Figure 1). Effects of copolymer composition and polyaniline addition on the filtration performance were evaluated. Furthermore, $\mathrm{pH}$ and dye concentration effects on the dye rejection values also analyzed in this study.

\section{MATERIALS AND METHODS}

\section{Materials}

Isopropyl alcohol (99,9\%), ammonium persulfate (98\%), sulfuric acid (95-97\%), 1dodecanethiol (98+\%), magnesium sulfate (99+\%), 1-methyl-2-pyrrolidonone $(99+\%)$ and N,Ndimethyl formamide $(99+\%)$ and polyaniline (PANI) were obtained from Sigma-Aldrich and used directly without purification. 2-ethylhexylacrylate (Sigma-Aldrich, 98\%) and acrylonitrile (SigmaAldrich, 99\%) were distilled before utilization. DOWFAX 8390 and methyl orange were also used as received.

\section{Copolymer Synthesis and Membrane Preparation}

Acrylonitrile and 2-ethylhexylacrylate were copolymerized by emulsion polymerization route in order to synthesize polyacrylonitrile-co-poly(2-ethylhexylacrylate) (Bozkir et al., 2012):

$20 \%$ of monomers, 1-dodecanethiol, DOWFAX $8390,60 \%$ of ammonium persulfate and water were put into a three-naked flask having termocouple, condenser, dropping funnel, stirrer and nitrogen inlet. Temperature was raised to $66^{\circ} \mathrm{C}$ and the solution was purged with nitrogen for $1 \mathrm{~h}$ before the compounds were mixed. The monomer mixture left was poured into the flash in $2 \mathrm{~h}$. Then, the remaining ammonium persulfate was added to the flask and the solution was stirred at $66^{\circ} \mathrm{C}$. After $1 \mathrm{~h}$, the copolymer was precipitated via $10 \mathrm{wt} \%$ aqueous $\mathrm{MgSO}_{4}$ solution and washed with distilled water several times. The obtained copolymer was vacuum dried at $60^{\circ} \mathrm{C}$ overnight. Copolymers were denoted as PAN(x)-co-P2EHA(y) where $\mathrm{x}$ and $\mathrm{y}$ indicate molar percents of acrylonitrile and 2ethylhexylacrylate in the copolymer, respectively.

For the membrane preparation from copolymers, $1.2 \mathrm{~g}$ copolymer was dissolved in $7.7 \mathrm{~g}$ dimethyl formamide overnight and casted on a smooth surfaced glass. After the solution was levelled, it was put into isopropyl alcohol. After $1 \mathrm{~h}$, it was immersed in distilled water and kept for overnight. In order to obtain PANI containing membranes, PANI and PAN(92)-co-P2EHA(8) copolymer were dissolved in dimethyl formamide. Then, membranes were produced via similar route described as above. For $10 \mathrm{wt} \%$ PANI including membrane, $0.12 \mathrm{~g}$ PANI and $1.08 \mathrm{~g}$ PAN(92)-co-P2EHA(8) were used and it was denoted as PAN(92)-co-P2EHA(8)/PANI(10\%).

\section{Membrane Characterization, Water Flux and Dye Rejection Tests}

The infrared spectra of membranes were utilized by Perkin Elmer Spectrum100 FTIR spectrometer. Water uptakes were evaluated by the equation:

$$
W U=\frac{m_{w}-m_{d}}{w_{d}}
$$

where $\mathrm{WU}, \mathrm{m}_{\mathrm{d}}$ and $\mathrm{m}_{\mathrm{w}}$ are weight percent water uptake, dry and wet weights of membranes, respectively.

Filtration tests were conducted by a dead end filtration method under the pressure of 1 bar. Permeate $\mathrm{pH}$ and concentrations were varied between 2-10 and 25-100 ppm, respectively. Filtration performances were utilized by Perkin Elmer Lambda $35 \mathrm{UV}-\mathrm{Vis}$ spectrometer at $465 \mathrm{~nm}$ (Zhu et al., 2016). Active area and thickness of membranes were about $8.0 \mathrm{~cm}^{2}$ and $200 \mu \mathrm{m}$, respectively.

Flux $(\mathrm{J})$ values were calculated by the following equation:

$$
J=\frac{V}{A t}
$$

where $\mathrm{V}, \mathrm{A}$ and are the volume $(\mathrm{L})$ of the filtrate, the active membrane area $\left(\mathrm{m}^{2}\right)$ and the time interval (h), respectively.

The percent rejection of methyl orange $(\mathrm{R})$ was calculated by the following equation:

$$
R=\left(1-\frac{C_{f}}{C_{i}}\right) x 100
$$


where $C_{i}$ and $C_{f}$ are initial and final concentrations of methyl orange solutions before and after filtration, respectively.

The membrane morphologies were evaluated by Quanta 400F Field Emission SEM scanning electron microscope.

\section{RESULTS AND DISCUSSION}

Infrared spectra of copolymer membranes and PANI containing membranes can be seen in Figure 2. Signals at 2254 and $2925 \mathrm{~cm}^{-1}$ were contributed to $\mathrm{C} \equiv \mathrm{N}$ and aliphatic $\mathrm{C}-\mathrm{H}$ stretchings of PAN-co-P2EHA copolymers, respectively. Moreover, the signal at $1455 \mathrm{~cm}^{-1}$ was associated with C-H bending. Furthermore, peaks at $1724 \mathrm{~cm}^{-1}$ and $1064-1273 \mathrm{~cm}^{-1}$ were related to $\mathrm{C}=\mathrm{O}$ and $\mathrm{C}-\mathrm{C}-\mathrm{O}, \mathrm{O}-\mathrm{C}-\mathrm{C}$ stretchings, respectively. Also, signals at 1644 and $1598 \mathrm{~cm}^{-1}$ were pertinent to quinoid and benzoid rings of PANI. Additionally, the signal observed at $1324 \mathrm{~cm}^{-1}$ was related to $\mathrm{C} \equiv \mathrm{N}$ angular deformation.

(a)

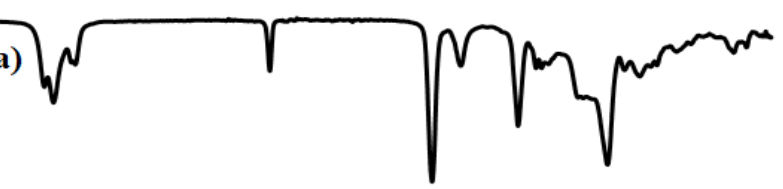

(b)
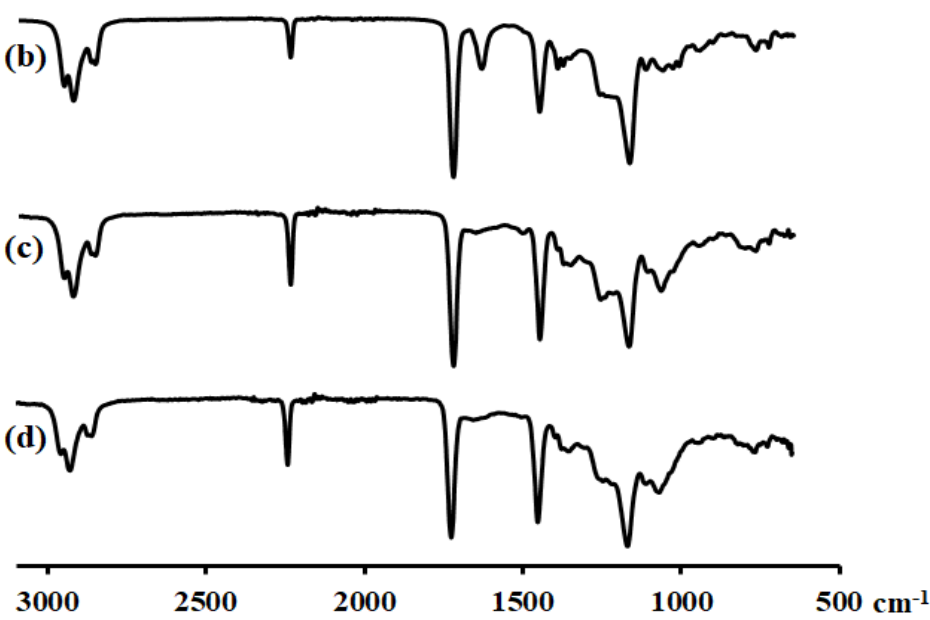

Figure 2. FTIR spectra of (a) PAN(84)-co-P2EHA(16), (b) PAN(92)-co-P2EHA(8), (c) PAN(92)-co-P2EHA(8)PANI $(5 \%)$ and (d) PAN(92)-co-P2EHA(8)-PANI(10\%) membranes

PAN(92)-co-P2EHA(8), PAN(92)-co-P2EHA(8)-PANI(5\%) and PAN(92)-co-P2EHA(8)PANI $(10 \%)$ membrane morphologies in Figure 3 showed that they had similar morphologies without any phase separation. Also, membranes seemed to have porous structure and pore features were estimated smaller than $100 \mathrm{~nm}$. These small features provided relatively low fluxes and enhanced the filtration performance of membranes. Also, since the functionality of membranes is another important effect for effective filtration besides the small pore size, functionalization of membranes by PANI incorporation was expected to further improve the filtration performance.

In Table 1, it can be seen that water uptake values of PAN(84)-co-P2EHA(16) and PAN(92)-coP2EHA(8) were alike. Since PANI provides hydrophilicity, PANI addition into membranes gave higher water uptake values. Also, water uptakes increased with the PANI content in the membrane. Thus, PAN(92)-co-P2EHA(8)- PANI(10\%) provided the highest water uptake value of $8.89 \%$ which was 3.3 times of the water uptake of PAN(92)-co-P2EHA(8). Moreover, increase in hydrophilicity led to higher water permeation. Thus, both water and permeate fluxes increased with PANI content in the membrane. As a result, while water fluxes of PAN(84)-co-P2EHA(16) and PAN(92)-co-P2EHA(8) were calculated as 62.8 and $56.6 \mathrm{~L} \mathrm{~m}^{-2} \mathrm{~h}^{-1}$, they were measured as 90.4 and $113.5 \mathrm{~L} \mathrm{~m}^{-2} \mathrm{~h}^{-1}$ for PAN(92)-co-P2EHA(8)-PANI(5\%) and PAN(92)-co-P2EHA(8)-PANI(10\%), respectively. It can be seen that water fluxes were enhanced by PANI content in the membrane proportionally. Furthermore, alike results were obtained for permeate fluxes and were calculated as 44.5 and $37.8 \mathrm{~L} \mathrm{~m}^{-2} \mathrm{~h}^{-1}$ for PAN(84)-co-P2EHA(16) and PAN(92)-co-P2EHA(8), 68.1 and $77.3 \mathrm{~L} \mathrm{~m}^{-2} \mathrm{~h}^{-1}$ for PAN(92)-coP2EHA(8)-PANI(5\%) and PAN(92)-co-P2EHA(8)-PANI(10\%), respectively. 

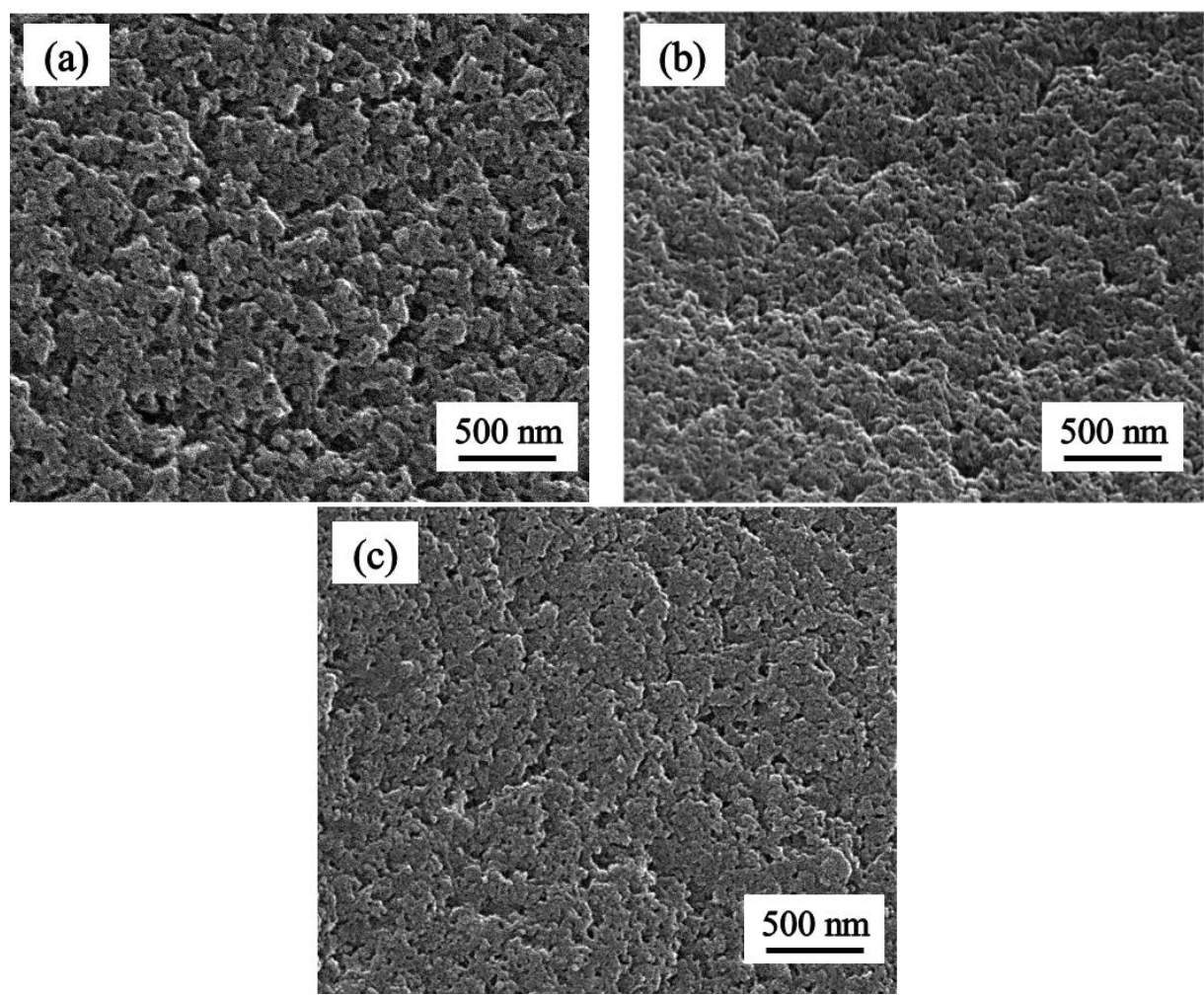

Figure 3. SEM morphologies of (a) PAN(92)-co-P2EHA(8), (b) PAN(92)-co-P2EHA(8)-PANI(5\%) and (c) PAN(92)-coP2EHA(8)- PANI(10\%) membranes

Table 1. Membrane features (The permeate concentration and $\mathrm{pH}$ were $25 \mathrm{ppm}$ and 7 , respectively.)

\begin{tabular}{lccc}
\hline Membrane & $\begin{array}{c}\text { Water uptake } \\
(\text { weight } \%)\end{array}$ & $\begin{array}{c}\text { Water flux } \\
\left(\mathrm{L} \mathrm{m}^{-2} \mathrm{~h}^{-1}\right)\end{array}$ & $\begin{array}{c}\text { Permeate flux } \\
\left(\mathrm{L} \mathrm{m}^{-2} \mathrm{~h}^{-1}\right)\end{array}$ \\
\hline PAN(84)-co-P2EHA(16) & 2.61 & 62.8 & 44.5 \\
PAN(92)-co-P2EHA(8) & 2.70 & 56.6 & 37.8 \\
PAN(92)-co-P2EHA(8)-PANI(5\%) & 5.88 & 90.4 & 68.1 \\
PAN(92)-co-P2EHA(8)-PANI(10\%) & 8.89 & 113.5 & 77.3 \\
\hline
\end{tabular}

The filtration performances of copolymer and PANI including membranes can be seen in Fig. 4. It shows that the filtration performance increased as the acrylonitrile content increased. This may be the result of the decrease in 2-ethylhexylacrylate amount that may lead to branching. Thus, this resulted in smaller pore features due to lower branching unit amount. In Table 1, it can be observed that both water and permeate flux values showed decrement as 2-ethylhexylacrylate amount decreased. The membrane resistance through permeation increased. This increase was also applied to dye molecules. As the acrylonitrile amount increased and fluxes decreased, the filtration performance of membranes increased. Lesser dye molecules could pass through the membrane due to the increase in membrane resistance towards permeation. The dye rejection values were measured as $38.4 \%$ and $52.8 \%$ for PAN(84)-co-P2EHA(16) and PAN(92)-co-P2EHA(8), respectively.

Since pore features and fluxes are not the only parameters that affect the filtration performance of membranes, membrane pores should be functionalized in order to enhance the rejection rates (Bozkir et al., 2012). For this purpose, PANI was added to PAN(92)-co-P2EHA(8). Figure 4 showed that PANI addition enhanced the filtration performance and this enhancement was proportional with PANI amount since higher PANI amount provided higher functionalization. Consequently, dye rejection values were calculated as $77.2 \%$ and $82.0 \%$ for PAN(92)-co-P2EHA(8)-PANI(5\%) and PAN(92)-co-P2EHA(8)- PANI(10\%), respectively.

In order to analyze the $\mathrm{pH}$ dependency of membranes towards dye rejection, $\mathrm{pH}$ was varied from 2 to 10 . The $\mathrm{pH}$ of permeate adjusted to 10 for the evaluation of basicity effect on the filtration performance of membranes. It was seen that both copolymer and PANI including membranes were not sensitive to basic medium. The filtration performances at $\mathrm{pH} 10$ were comparable with the ones at $\mathrm{pH}$ 
7. On the other hand, when $\mathrm{pH}$ was set to 5 and medium became acidic, although the filtration performance of copolymer membranes did not showed significant changes, PANI containing membranes showed enhanced filtration performance. This may be the result of the functionality of PANI in acidic mediums. It was turned from emeraldine base form to emeraldine salt form and positively charged in acidic environments. Thus, the interaction between the positively charged membrane and negatively charged dye molecules increased. As a result, the dye rejection rates of PANI containing membranes increased with decreasing $\mathrm{pH}$. Also, it was seen that this increase was proportional to PANI amount in the membrane. Dye rejection values were calculated as $84.4 \%$ and 91.1\% for PAN(92)-co-P2EHA(8)-PANI(5\%) and PAN(92)-co-P2EHA(8)- PANI(10\%), respectively when $\mathrm{pH}$ was set as 5. Furthermore, when $\mathrm{pH}$ was dropped to 2, the filtration performance of PANI containing membranes was further improved. Also, it increased with the PANI content in the membrane and this increase was sharper when compared the one at $\mathrm{pH} 5$. The filtration performance became more dependent on PANI content $\mathrm{pH}$ further decreased. Dye rejection values at $\mathrm{pH} 2$ was found as $88.3 \%$ and $99.3 \%$ for PAN(92)-co-P2EHA(8)-PANI(5\%) and PAN(92)-co-P2EHA(8)PANI(10\%), respectively.

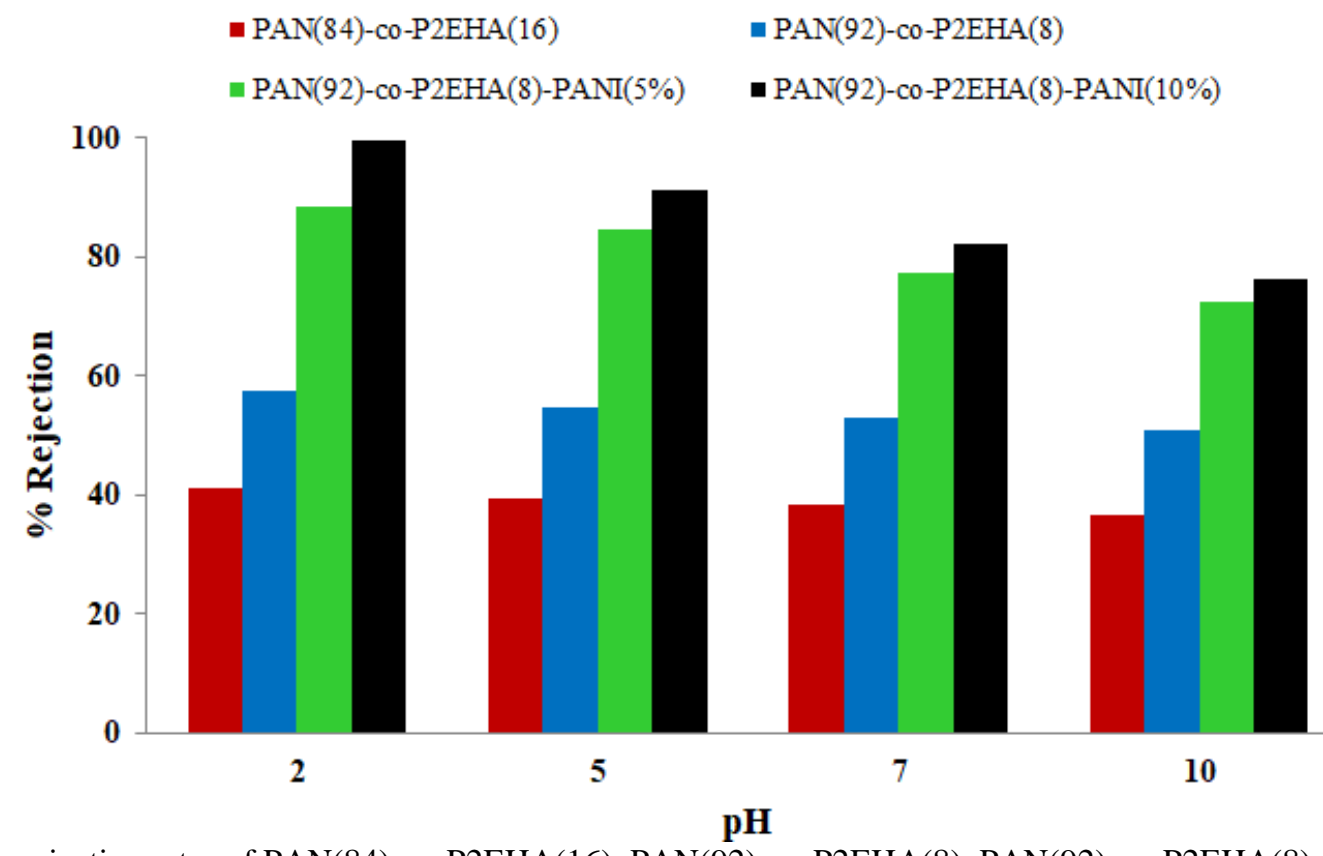

Figure 4. Dye rejection rates of PAN(84)-co-P2EHA(16), PAN(92)-co-P2EHA(8), PAN(92)-co-P2EHA(8)-PANI(5\%) and PAN(92)-co-P2EHA(8)- PANI(10\%) membranes at $\mathrm{pH} \mathrm{2,} \mathrm{5,} 7$ and 10 (The permeate concentration was $25 \mathrm{ppm}$ )

In order to analyse the concentration effect on the membrane filtration performance, PAN(92)co-P2EHA(8)- PANI(10\%) was utilized for the filtration of permeates having 25-100 ppm dye concentration at various pHs. As can be seen in Figure 5, dye rejection rates were strongly influenced by the permeate concentration at $\mathrm{pH} 7$ and 10. This may be due to behaviours of copolymer and PANI in basic ant neutral mediums. The membrane was not functional and positively charged at these mediums. Thus, the interaction between dye molecules and the membrane was not strong and the filtration performance depended on pore features of the membrane. As a result, the resistance of membrane towards permeate concentration was poor. Dye rejection rates were calculated as $82.0 \%$, $70.1 \%, 49.3 \%$ at $\mathrm{pH} 7$ and $76.2 \%, 62.1 \%, 38.4 \%$ at $\mathrm{pH} 10$ for 25,50 and $100 \mathrm{ppm}$, respectively (Figure 5). On the other hand, when $\mathrm{pH}$ decreased to 5 and the environment was made acidic, the membrane showed more resistance to increase in the permeate concentration. This may arise from the conversion of PANI from emeraldine base to emeraldine salt that led to positively charged membrane. Thus, the interaction between negative dye molecules and the positive membrane enhanced. Therefore, in addition to pore features, this attraction improved the filtration performance.

Hence, dye rejection rates at $\mathrm{pH} 5$ were found as $91.1 \%, 85.3 \%$, and $75.3 \%$ for 25,50 and 100 $\mathrm{ppm}$, respectively. Furthermore, when $\mathrm{pH}$ further decreased to 2, the membrane demonstrated higher 
filtration resistance towards the permeate concentration. This may be the result of the increase in the acidity of the environment and its increased effect on the functionality of PANI. The dye rejection rate was obtained as $99.3 \%$ when the permeate concentration was $25 \mathrm{ppm}$. Moreover, when the permeate concentration was increased to $50 \mathrm{ppm}$, the filtration performance of the membrane was conserved and the dye rejection value was found as $97.6 \%$. Furthermore, even though the permeate concentration was further increased to $100 \mathrm{ppm}$, the membrane showed good resistance to this increase and its filtration performance did not show significant decrease. The dye rejection rate was measured as $90.1 \%$. Moreover, when the rejection rates were compared with values in literature, it was observed that PAN(92)-co-P2EHA(8)-PANI(10\%) could exhibit satisfactory dye rejection performance (Table 2).

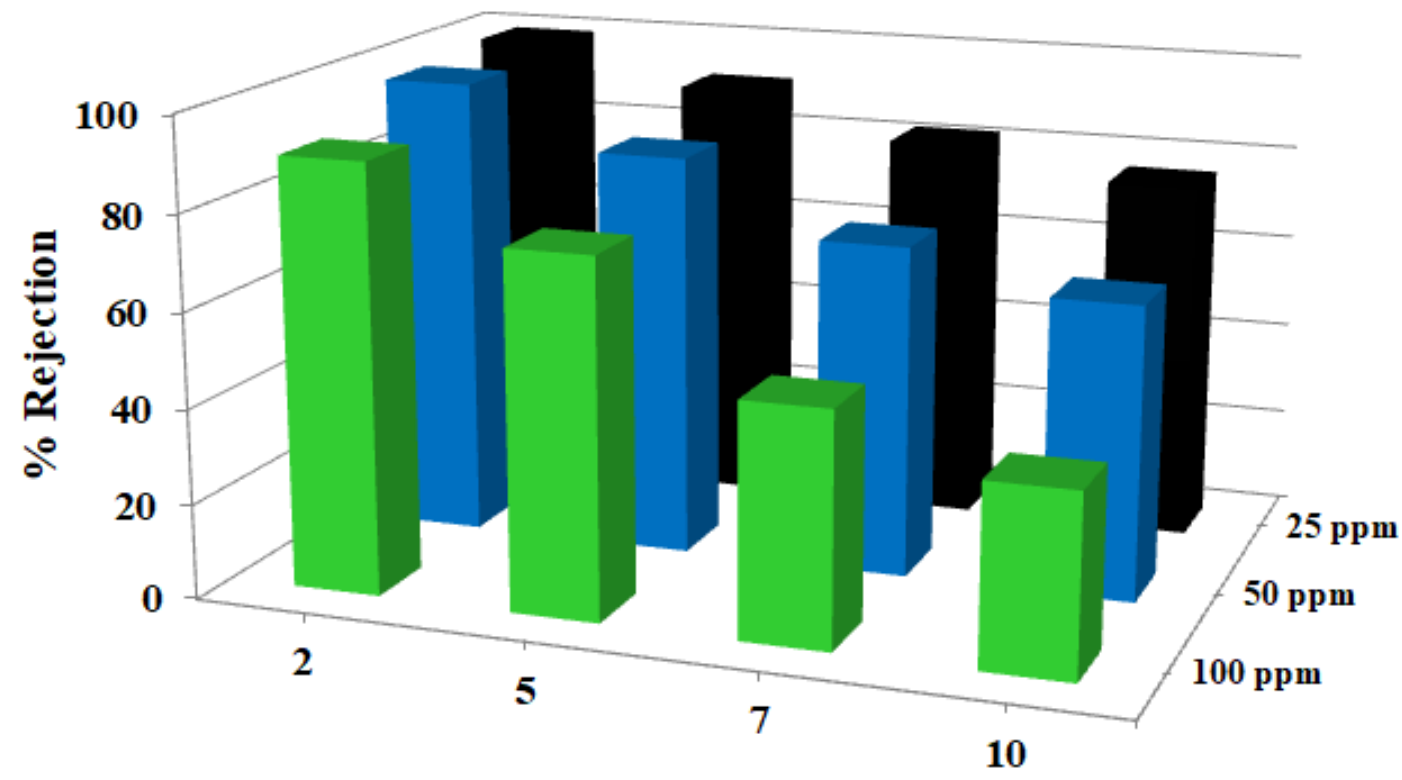

pH

Figure 5. Dye rejection rates of PAN(92)-co-P2EHA(8)- PANI(10\%) membranes against permeate concentrations of 25 , 50 and $100 \mathrm{ppm}$ at $\mathrm{pH} \mathrm{2,} \mathrm{5,} 7$ and 10

Table 2. Methyl orange rejection rates of various membranes

\begin{tabular}{|c|c|c|c|}
\hline Membrane & Permeate Concentration (ppm) & Dye Rejection (\%) & Reference \\
\hline PAN-tannic acid-cupric acetate & 10 & 65 & Chakrabarty et al., 2017 \\
\hline Polyamide6@GO@PA 6-TiO ${ }_{2}$ & 10 & 99.36 & Chen et al., 2018 \\
\hline PS-PDA-CS- $\mathrm{SiO}_{2}$ & 20 & 97.6 & Ding et al., 2017 \\
\hline Nanoclay-zeolite & $20-70$ & 10 & Foorginezhad and Zerafat, 2017 \\
\hline Zirconia-ceramic & 3000 & 61 & Kumar et al., 2015 \\
\hline MgSi@RGO/PAN & 100 & 73.4 & Liang et al., 2016 \\
\hline PDA-polyethyleneimine- $\beta-\mathrm{FeOOH}$ & 20 & 69.9 & Lv et al., 2017 \\
\hline PVDF & 11 & 80 & Mertens et al., 2018 \\
\hline PAN-polyamide & 11 & 30 & Perez-Manriquez et al., 2015 \\
\hline Carboxylated MWCNTs-Chitosan & 5 & 83.6 & Shi et al., 2016 \\
\hline Polyurethane foam-humic acid-chitosan & 5 & 99.7 & Yang et al., 2017 \\
\hline \multirow{2}{*}{ GO- isophorone diisocyanate } & 10 & 97.7 & Zhang et al., 2017 \\
\hline & 25 & 99.3 & \\
\hline \multirow[t]{2}{*}{ PAN(92)-co-P2EHA(8)-PANI(10\%) } & 50 & 97.6 & This study \\
\hline & 100 & 90.1 & \\
\hline
\end{tabular}

\section{CONCLUSION}

In this study, the filtration of methyl orange by PAN-co-P2EHA and PAN-co-P2EHA/PANI membranes were utilized. It was observed that the filtration performance increased as 2ethylhexylacrylate amount in the copolymer decreased. Furthermore, PANI addition enhanced dye rejection rates and they were proportional with PANI amount in the membrane. Also, the filtrate,on performance of PANI containing membranes further increased in acidic mediums. When $\mathrm{pH}$ decreased, their filtration performances improved significantly. PAN(92)-co-P2EHA(8)- PANI(10\%) membrane showed the highest dye rejection rate of $99.3 \%$ at $\mathrm{pH} 2$ and $25 \mathrm{ppm}$. Moreover, this 
membrane demonstrated good resistance to the permeate concentration. The dye rejection rates were found as $97.6 \%$ and $90.1 \%$ when the permeate concentration increased to 50 and $100 \mathrm{ppm}$, respectively. Consequently, PAN(92)-co-P2EHA(8)- PANI(10\%) may be regarded as a good alternative for the filtration of methylene orange.

\section{ACKNOWLEDGEMENTS}

This study was supported financially by The Research Centre of Amasya University under the project number FMB-BAP 17-0266.

\section{REFERENCES}

Ahmad A, Mohd-Setapar S H, Chuong C S, Khatoon A, Wani W A, Kumar R, Rafatullah M, 2015. Recent advances in new generation dye removal technologies: novel search for approaches to reprocess wastewater. RSC Advances, 5:30801-30818.

Aouni A, Fersi C, Cuartas-Uribe B, Bes-Pia A, Alcaina-Miranda M I, Dhahbi M, 2012. Reactive dyes rejection and textile effluent treatment study using ultrafiltration and nanofiltration processes. Desalination, 297:87-96.

Bozkir S, Sankir M, Semiz L, Sankir N D, Usanmaz A, 2012. High performance chromium (VI) removal from Water by polyacrylonitrile-co-poly (2-ethyl hexylacrylate) and polyaniline nanoporous membranes. Polymer Engineering \& Science, 52:1613-1620.

Chakrabarty T, Perez-Manriquez L, Neelakanda P, Peinemann K-V, 2017. Bioinspired tannic acid-copper complexes as selective coating for nanofiltration membranes. Separation and Purification Technology, 184:188-194.

Chen H, Zheng Y, Cheng B, Yu J, Jiang C, 2018. Chestnut husk-like nickel cobaltite hollow microspheres for the adsorption of Congo red. Journal of Alloys and Compounds, 735:1041-1051.

Chen L, Li N, Wen Z, Zhang L, Chen Q, Chen L, Si P, Feng J, Li Y, Lou J, Ci L, 2018. Graphene oxide based membrane intercalated by nanoparticles for high performance nanofiltration application. Chemical Engineering Journal, 347:12-18.

Chen L, Li Y, Chen L, Li N, Dong C, Chen Q, Liu B, Ai Q, Si P, Feng J, Zhang L, Suhr J, Lou J, Ci L. 2018. A large-area free-standing graphene oxide multilayer membrane with high stability for nanofiltration applications. Chemical Engineering Journal, 345:536-544.

Chen X, Zhao YY, Moutinho J, Shao J, Zydney A L, He Y, 2015. Recovery of small dye molecules from aqueous solutions using charged ultrafiltration membranes. Journal of Hazardous Materials, 284:58-64.

Ding W, Zhuo H, Bao M, Li Y, Lu J, 2017. Fabrication of organic-inorganic nanofiltration membrane using ordered stacking $\mathrm{SiO}_{2}$ thin film as rejection layer assisted with layer-by-layer method. Chemical Engineering Journal, 330:337-344.

Fathizadeh M, Tien H N, Khivantsev K, Chen J-T, Yu M, 2017. Printing ultrathin graphene oxide nanofiltration membranes for water purification. Journal of Materials Chemistry A, 5:20860-20866.

Foorginezhad S, Zerafat M M, 2017. Microfiltration of cationic dyes using nano-clay membranes. Ceramics International, 43:15146-15159.

Gao H, Kan T, Zhao S, Qian Y, Cheng X, Wu W, Wang X, Zheng L, 2013. Removal of anionic azo dyes from aqueous solution by functional ionic liquid cross-linked polymer. Journal of Hazardous Materials, 261:83-90.

Han G, Liang C-Z, Chung T-S, Weber M, Staudt C, Maletzko C, 2016. Combination of forward osmosis (FO) process with coagulation/flocculation $(\mathrm{CF})$ for potential treatment of textile wastewater. Water Research, 91:361-370.

Jiang T, Liang Y-D, He Y-J, Wang Q, 2015. Activated carbon/ $\mathrm{NiFe}_{2} \mathrm{O}_{4}$ magnetic composite: A magnetic adsorbent for the adsorption of methyl orange. Journal of Environmental Chemical Engineering, 3:17401751.

Karthik V, Saravanan K, Bharathi P, Dharanya V, Meiaraj C, 2014. An overview of treatments for the removal of textile dyes. Journal of Chemical and Pharmaceutical Sciences, 7:301-307.

Kertesz S, Cakl J, Jirankova H, 2014. Submerged hollowfibermicrofiltration as a part of hybrid photocatalytic process for dye wastewater treatment. Desalination, 343:106-112.

Kumar R V, Ghoshal A K, Pugazhenthi G, 2015. Fabrication of zirconia composite membrane by in-situ hydrothermal technique and its application in separation of methyl orange. Ecotoxicology and Environmental Safety, 121:73-79. 
Kumar V, Karnjkar Y, George P, Singh R K, Chowdhury P, 2018. Effective removal of Congo red using sunflower oil/tri-n-octylamine system in a bulk liquid membrane process and studying the transport kinetics. Chemical Papers, 72:2055-2069.

Li P, Song Y, Wang S, Tao Z, Yu S, Liu Y, 2015. Enhanced decolorization of methyl orange using zero-valent copper nanoparticles under assistance of hydrodynamic cavitation. Ultrasonics Sonochemistry, 22:132138.

Liang B, Zhang P, Wang J, Qu J, Wang L, Wang X, Guan C, Pan K, 2016. Membranes with selective laminar nanochannels of modified reduced graphene oxide for water purification. Carbon, 103:94-100.

Lin J, Tang C Y, Ye W, Sun S-P, Hamdan S H, Volodin A, Van Haesendonck C, Sotto A, Luis P, Van der Bruggen B, 2015. Unraveling flux behavior of super hydrophilic loose nanofiltration membranes during textile wastewater treatment. Journal of Membrane Science, 493:690-702.

Liu C, Cheng L, Zhao Y, Zhu L, 2017. Interfacially crosslinked composite porous membranes for ultrafastremoval of anionic dyes from water through permeating adsorption. Journal of Hazardous Materials, 337:217-225.

Liu M, Chen Q, Lu K, Huang W, Lü Z, Zhou C, Yu S, Gao C, 2017. High efficient removal of dyes from aqueous solution through nanofiltration using diethanolamine-modified polyamide thin-film composite membrane. Separation and Purification Technology, 173:135-143.

Luo D-H, Zheng Q-K, Chen S, Liu Q-S, Wang X-X, Guan Y, Pu Z-Y, 2010. Decolorization and degradation of reactive dye during the dyed cotton fabric rinsing process. Water Science \& Technology, 62:766-775.

Lv Y, Zhang C, He A, Yang S-J, Wu G-P, Darling S B, Xu Z-K, 2017. Photocatalytic Nanofiltration Membranes with Self-Cleaning Property for Wastewater Treatment. Advanced Functional Materials, 27(1700251):1-8.

Manimaran D, Sulthana A S, Elangovan N, 2018. Reactive black 5 induced developmental defects via potentiating apoptotic cell death in Zebrafish (Danio rerio) embryos. Pharmacy and Pharmacology International Journal, 6:449-452.

Mertens M, Van Dyck T, Van Goethem C, Gebreyohannes A Y, Vankelecom I F J, 2018. Development of a polyvinylidene difluoride membrane for nanofiltration. Journal of Membrane Science, 557:24-29.

Nabil G M, El-Mallah N M, Mahmoud M E, 2014. Enhanced decolorization of reactive black 5 dye by active carbon sorbent-immobilized-cationic surfactant (AC-CS). Journal of Industrial and Engineering Chemistry, 20:994-1002.

Nayak M C, Isloor A M, Moslehyani A, Ismail N, Ismail A F, 2018. Fabrication of novel PPSU/ZSM-5 ultrafiltration hollow fiber membranes for separation of proteins and hazardous reactive dyes. Journal of the Taiwan Institute of Chemical Engineers, 82:342-350.

Ong Y K, Li F Y, Sun S-P, Zhao B-W, Liang C-Z, Chung T-S, 2014. Nanofiltration hollow fiber membranes for textile wastewater treatment: Lab-scale and pilot-scale studies. Chemical Engineering Science, 114:51-57.

Ou W, Zhang G, Yuan X, Su P, 2015. Experimental study on coupling photocatalytic oxidation process and membrane separation for the reuse of dye wastewater. Journal of Water Process Engineering, 6:120-128.

Panthi G, Park M, Kim H-Y, Lee S-Y, Park S-J, 2015. Electrospun ZnO hybrid nanofibers for photodegradation of wastewater containing organic dyes: A review. Journal of Industrial and Engineering Chemistry, 21:26-35.

Perez-Manriquez L, Aburabi’e J, Neelakanda P, Peinemann K-V, 2015. Cross-linked PAN-based thin-film composite membranes for non-aqueous nanofiltration. Reactive and Functional Polymers, 86:243-247.

Shi J, Wu T, Teng K, Wang W, Shan M, Xu Z, Lv H, Deng H, 2016. Simultaneous electrospinning and spraying toward branch-like nanofibrous membranes functionalised with carboxylated MWCNTs for dye removal. Materials Letters, 166:26-29.

Thong Z, Gao J, Lim J X Z, Wang K-Y, Chung T-S, 2018. Fabrication of loose outer-selective nanofiltration (NF) polyethersulfone (PES) hollow fibers via single-step spinning process for dye removal. Separation and Purification Technology, 192:483-490.

Wang Z, Guo J, Ma J, Shao L, 2015. Highly regenerable alkali-resistant magnetic nanoparticles inspired by mussels for rapid selective dye removal offer high-efficiency environmental remediation. Journal of Materials Chemistry A, 3:19960-19968.

Xing L, Guo N, Zhang Y, Zhang H, Liu J, 2015. A negatively charged loose nanofiltration membrane by blending with poly (sodium 4-styrene sulfonate) grafted $\mathrm{SiO}_{2}$ via SI-ATRP for dye purification. Separation and Purification Technology, 146:50-59. 
Xu H-M, Sun X-F, Wang S-Y, Song C, Wang S-G, 2018. Development of laccase/graphene oxide membrane for enhanced synthetic dyes separation and degradation. Separation and Purification Technology, 204:255-260.

Xu Y C, Wang Z X, Cheng X Q, Xiao Y C, Shao L, 2016. Positively charged nanofiltration membranes via economically mussel-substance-simulated co-deposition for textile wastewater treatment. Chemical Engineering Journal, 303:555-564.

Yang H-C, Gong J-L, Zeng G-M, Zhang P, Zhang J, Liu H-Y, Huan S-Y, 2017. Polyurethane foam membranes filled with humic acid-chitosan crosslinked gels for selective and simultaneous removal of dyes. Journal of Colloid and Interface Science, 505:67-78.

Yao L, Zhang L, Wang R, Chou S, Dong Z, 2016. A new integrated approach for dye removal from wastewater bypolyoxometalates functionalized membranes. Journal of Hazardous Materials, 301:462-470.

Zhang N, Jiang B, Zhang L, Huang Z, Sun Y, Zong Y, Zhang H, 2019. Low-pressure electroneutral loose nanofiltration membranes with polyphenol-inspired coatings for effective dye/divalent salt separation. Chemical Engineering Journal, 359:1442-1452.

Zhang P, Gong J-L, Zeng G-M, Deng C-H, Yang H-C, Liu H-Y, Huan S-Y, 2017. Cross-linking to prepare composite graphene oxide-framework membranes with high-flux for dyes and heavy metal ions removal. Chemical Engineering Journal, 322:657-666.

Zhu J, Zheng J, Liu C, Zhang S, 2016. Ionic complexing induced fabrication of highly permeable and selective polyacrylic acid complexed poly (arylene ether sulfone) nanofiltration membranes for water purification. Journal of Membrane Science, 520:130-138. 